\title{
Deleuze pedagogo: ou a voz do mestre de Vincennes ${ }^{1}$
}

\section{Resumo}

Os anos pós 68 na França foram marcados por um intenso período de experimentação pedagógica, sobretudo no ensino superior. No quadro deste artigo, interessamo-nos pelas práticas pedagógicas dos professores de filosofia da Universidade experimental Paris VIII Vincennes, centrando-nos particularmente naquelas de Gilles Deleuze. E, ao contrário da imagem que geralmente se tem, mostraremos que tais atividades eram, para resumir, altamente magistrais e que haviam retomado principalmente as vias da pedagogia carismática a mais tradicional.

Palavras-chave: Pedagogia; Filosofia; Gilles Deleuze; Carisma; Paris VIII Vincennes.

\section{Charles Soulié}

Doutor em Sociologia pela École des Hautes Études en Sciences

Sociales - EHESS - Paris/França charles.soulie@neuf.fr

\section{Para citar este artigo:}

SOULIÉ, Charles. A pedagogia carismática de Gilles Deleuze na Universidade de Vincennes. Revista Linhas. Florianópolis, v. 16, n. 32, p. 286 - 314, set./dez. 2015. Título original: Deleuze pédagogue: ou la voix du maître de Vincennes. Traduzido por Fernando Coelho e Nelson M. Coelho Junior, com revisão técnica de Ione Ribeiro Valle.

\section{DOI: $10.5965 / 1984723816322015286$}

http://dx.doi.org/10.5965/1984723816322015286

\footnotetext{
${ }^{1}$ Este texto tem origem em conferência proferida por Charles Soulié em Florianópolis em outubro de 2014. A atividade aconteceu no Centro de Ciências da Educação da Universidade Federal de Santa Catarina e resultou de uma parceria entre os Programas de Pós Graduação em Educação da Universidade do Estado de Santa Catarina - UDESC e a anfitriã. Tradução de Fernando Coelho e Nelson M. Coelho Junior, revisão técnica de Ione Ribeiro Valle.
} 


\title{
Deleuze as pedagogue: or the voice of the master of Vincennes
}

\begin{abstract}
The years after 1968 in France were characterized by an intense period of pedagogic experimentation, mainly in higher education. In this article, we are interested in the pedagogic practices of the philosophy of the experimental University of Vincennes Paris VIII, focusing in particular those of Gilles Deleuze. And, contrary to the image that one generally has, we show that such activities were, to summarize, highly magistral, taking the path of the most traditional charismatic pedagogy.
\end{abstract}

Keywords: Pedagogy; Philosophy; Gilles Deleuze; Charism; Paris VIII Vincennes. 
Este texto,

Em forma de homenagem àquele que soube,

Como ninguém,

Jogar para o alto os moinhos da pompa acadêmica,

Abolir as fronteiras da seriedade e da alegria,

Do pensamento e do prazer,

Da Filosofia e da política

E, por suas provocações para pensar,

Comunicar seu humor subversivo

A todos os agitadores de ideias,

Mas também de palavras, de sons ou de imagens.

Primeiramente, meus cumprimentos a todas e a todos. Agradeço a Ione Valle pela organização desta conferência. Neste momento, gostaria de retomar e de aprofundar o artigo que acabo de publicar na revista Linhas $^{3}$. Na verdade, este artigo versa sobre uma tentativa de democratização universitária ocorrida na França pela Universidade Experimental de Vincennes nos anos 1970. Retomarei portanto esta história, concentrando-me desta vez na tentativa do Departamento de Filosofia. Interesso-me, particularmente, pela pedagogia carismática de Gilles Deleuze, procurando descrever alguns dos seus desdobramentos.

A questão que me interessa aqui diz respeito, por conseguinte, à pedagogia da filosofia. E mais precisamente à maneira pela qual - para falar como Sartre -filósofos “suficientemente reconhecidos" deram a ela uma resposta prática. Meu plano será o seguinte. Primeiramente, descreverei o contexto histórico e político de criação da Universidade de Vincennes, assim como o seu Departamento de Filosofia. Em seguida, passarei às práticas pedagógicas dos filósofos de Vincennes, concentrando-me mais especificamente nas de Deleuze. Com efeito, algumas publicações recentes permitem prolongar análises já delineadas em outros textos. Descreverei, portanto, sua trajetória, sua formação, para chegar à sua prática pedagógica e ao seu público.

\footnotetext{
${ }^{2}$ Pierre Bourdieu, Liber, 28, septembre, 1996.

${ }^{3} \mathrm{O}$ autor se refere ao artigo, intitulado: "Uma tentativa de democratização universitária na França: história da Universidade de Paris VIII Vincennes (1968-1980)”, publicado na Revista Linhas em 2014. Disponível em: http://www.revistas.udesc.br/index.php/linhas/article/view/1984723815292014042/pdf_2.(N.T.)
} 
Como se pode ver, este é um trabalho de sociologia da filosofia. Isto quer dizer que visarei o funcionamento da instituição filosófica francesa e alguns dos seus mais prestigiosos agentes, exercício este que poderá chocar alguns de vocês que apreciam sua obra. Mas esse não é o meu objetivo. Na verdade, meu objetivo é lançar luz sobre o funcionamento desta instituição e, mais precisamente, descrever algumas das condições sociais que possibilitaram determinadas práticas pedagógicas mais ou menos carismáticas, mas também, in fine, algumas produções teóricas. Com efeito, e como escrevera Marx, “Os filósofos não brotam da terra como cogumelos, eles são os frutos da sua época, do seu povo, cujos humores mais sutis, mais preciosos e menos visíveis circulam nas ideias filosóficas" ${ }^{4}$. Eu acredito que é papel das ciências sociais e históricas descrever essas condições e, assim, desenvolver uma forma de inteligibilidade específica dessas práticas e pensamentos. Considerando que, no caso de Deleuze, me parece que sua prática pedagógica permite esclarecer sua filosofia, e inversamente.

\section{A criação de Vincennes}

Os filósofos de profissão geralmente não se interessam muito pelas questões pedagógicas. Na verdade, tudo se passa como se, repetindo as famosas palavras de um antigo decano da Inspeção Geral de filosofia do ensino secundário na França, a filosofia é “ela mesma sua própria pedagogia”, e assim é como se bastasse ser filósofo para, de fato, ser capaz de transmitir esse saber. Enfim, a reflexão sobre a pedagogia e, de modo geral, sobre as condições sociais, materiais, institucionais, etc., do ensino da filosofia, frequentemente ocupam um espaço muito limitado na reflexão filosófica (pelo fato de Sócrates ter se tornado funcionário, observa-se certamente de tempos em tempos mobilizações de caráter corporativista visando sobretudo "defender o ensino da filosofia"). Mas a rejeição a pedagogia parece ser bastante difundida, e o que a filosofia deve à sua inscrição social, institucional e burocrática geralmente não é muito estudado. Tudo leva a crer que a filosofia encontrou na universidade o seu "lugar natural". O que

\footnotetext{
${ }^{4}$ Karl Marx, éditorial n ${ }^{\circ} 179$ de la Gazette de Cologne. Texto reproduzido em Karl Marx et Friedrich Engels, Sur la religion, Les éditions sociales, 1968. Disponible sur: https://www.marxists.org/francais/marx/works/oo/religion/Marx_Engels_sur_la_religion.pdf.
} 
alguns justificarão evocando como exemplo os exemplos prestigiosos de Kant, Hegel, Nietzsche, Heidegger, etc.

Antes de passar à história do Departamento de Filosofia de Vincennes, é necessário relatar alguns elementos de contextualização histórica. Na verdade, este Departamento, e de modo mais geral a Universidade de Vincennes, foram criados na sequência dos acontecimentos de maio de 68. É difícil resumir brevemente esses eventos. Digamos simplesmente que uma grande crise da universidade, ligada especialmente à rápida expansão do número tanto de estudantes quanto de professores, servirá como detonador para uma crise social de grande amplitude, que ocasionará notadamente uma das maiores greves operárias da história da França. De um lado, os estudantes aliados à fração modernizadora e vanguardista do mundo acadêmico abaterão a universidade mandarina a moda antiga. De outro, os operários, os assalariados entrarão em greve e ocuparão suas fábricas, a fim de obter aumentos salariais e mais direitos sociais.

Aqui é necessário falar do espírito revolucionário e utópico que, tanto na França como em outros lugares, animará boa parte da juventude estudantil da época, e que a conduzirá notadamente a promover valores de liberdade e de igualdade, no seio de um universo acadêmico com funcionamento ainda muito feudal. Ou, como diz um famoso slogan da época: “Todo professor é aprendiz. Todo aprendiz é professor”.

Os estudantes não criticam somente a relação de dominação pedagógica tradicional. Os mais radicais dentre eles, inspirados sobretudo no marxismo, quer seja trotskista, maoísta ou outro, têm aspirações revolucionárias e querem destruir a estrutura de classes da sociedade francesa. Em suma, a crítica social é altamente desenvolvida no meio estudantil e, sob a influência da obra Os Herdeiros, de Pierre Bourdieu e Jean-Claude Passeron, publicada em 1964 e recentemente traduzida para o português, ela os leva a criticar as funções de classe da universidade francesa e, portanto, sua contribuição à reprodução das desigualdades sociais. Daí decorre, após 68 , a vontade de abrir a universidade para todos, e mais especificamente para os trabalhadores, para aqueles que não possuíam o bacharelado [ou baccalauréat ${ }^{5}$ ], etc. Foi isso o que fez o Centro Universitário Experimental de Vincennes, futura Universidade de Paris VIII.

\footnotetext{
${ }^{5}$ Exames nacionais realizados no final dos estudos do liceu (ou do ensino médio) visando conferir o grau de bacharel; requisito até então obrigatório para o acesso ao Ensino Superior. (N.T.)
} 


\section{Departamento de Filosofia da Vincennes}

Foucault é o primeiro diretor do Departamento de Filosofia desta Universidade. Ele recém chegara da Tunísia e, portanto, como se costumava dizer, não havia "feito 68". Ou seja, ele não havia estado nas barricadas, nas comissões de reflexão da Sorbonne, muito ativas durante os eventos de 68 , etc. E, portanto, ele mal conhecia o meio dos jovens filósofos engajados. Em relação à admissão dos professores do Departamento, ele busca conselhos junto a um jovem normalista "brilhante" da época, a saber: Alain Badiou. Além disso, ele tenta apreender o conjunto das sensibilidades políticas da época, sabendo que os maoístas serão nitidamente majoritários nesse Departamento.

Inicialmente, Foucault deseja criar uma equipe epistemologicamente coerente e manter seu Departamento sob controle. Mas ele se desencanta rapidamente. Com efeito, desde a primeira reunião preparatória em sua casa no outono de 68 , um conflito eclode. Etienne Balibar propõe direcionar o ensino para a epistemologia, o estudo das ciências, assim como o estudo dos "grandes textos". E com isso ele se opõe à Foucault, que acha o seu programa: "um pouco antiquado, um pouco acadêmico." Assim como Jacques Rancière, que lhe retorque: "Tu nos faz crer que há um saber, mas o saber é uma realidade política, é a revolta estudantil, não é uma técnica." Visando dar um aspecto mais acadêmico ao ensino, Balibar é apoiado em especial por François Châtelet; esses professores passam a formar o que Jacques Rancière denominava como "o clã do saber". ${ }^{7}$

Esse conflito se prolonga, e se amplia, desde o início das aulas, e o Departamento se transforma em lugar de lutas políticas ferozes entre grupos políticos revolucionários rivais. Da mesma forma, o ambiente de pressão política muito intenso contribui para a evolução rápida dos programas de ensino. Na verdade, muitos estudantes estão procurando ferramentas de racionalização da luta política, assim como armas teóricas que possam ajudá-los no seu combate revolucionário. E se - conforme o projeto epistemológico inicial de Foucault - o programa de 1968/1969 inclui aulas de lógica,

\footnotetext{
${ }^{6}$ Egresso da prestigiosa Escola Normal Superior (ENS). (N.T.)

${ }^{7}$ Extraído de uma entrevista de Jacques Rancière realizada por Assia Melamed. Esta entrevista está na base dos arquivos relativos à história de Vincennes, tendo sido depositada por A. Melamed (ex-secretária do Departamento de Filosofia de Vincennes, de 1968 à 1973) na Biblioteca de Documentação Internacional de Nanterre.
} 
história e filosofia das ciências, estas desaparecem rapidamente em favor de ensinos de caráter mais político, que claramente respondem melhor à demanda estudantil. (Eis o que diz, por exemplo, Michel Serres, que permanece apenas um ano em Vincennes, indo estabelecer-se em seguida na Sorbonne: “Eu tive a impressão de estar mergulhado na mesma atmosfera de terrorismo intelectual que os stalinistas faziam reinar; quando eu era um estudante da Rua d’Ulm.”8 (Isto é, na Escola Normal Superior que, na França, é uma das grandes escolas onde se forma a elite intelectual do país).

Da mesma forma, a história da filosofia, que constitui, todavia, o fundamento habitual dos programas de ensino em filosofia, vê seu lugar diminuir, ainda que se observe que frequentemente são os professores mais velhos que continuam lecionando nos moldes tradicionais, e que, portanto, dão aulas sobre os grandes autores da história da filosofia, ou em vias de consagração. Assim, no primeiro ano, Foucault ensina sobre Nietzsche, Serres sobre o positivismo, Châtelet sobre o pensamento político grego. Enquanto Rancière, do seu lado, ministra um curso intitulado: "Revisionismo, esquerdismo" e outro intitulado: “A terceira etapa do marxismo leninista: o maoísmo”, Badiou ensina sobre "A ciência na luta das classes", ao passo que Henry Weber ensina sobre "Os escritos de Mao Tse-tung", etc. ${ }^{9}$.

Não somente o Departamento de filosofia se torna um vespeiro político ingovernável, como também os professores se tornam incapazes de chegar a um acordo sobre um programa de ensino mínimo e práticas de ensino comuns. De fato, e como resume de forma lapidar Jacques Rancière: “Experimental, isso queria dizer que cada um fazia o que queria." Ressurge então o individualismo pedagógico tradicional dos universitários franceses, mas elevado ao seu paroxismo e generalizado ao conjunto dos professores em razão do vigor do espírito anti-hierárquico da época. Assim, rapidamente cada professor, independentemente do seu estatuto, se torna livre para ensinar o que quer. Cabe a ele conseguir seu público, uma vez que os estudantes devem compor livremente o menu de sua licenciatura em filosofia. Um dos paradoxos resultantes desta experiência que visava, contudo, democratizar o acesso ao saber é que os filósofos de

\footnotetext{
${ }^{8}$ Cf. Didier Éribon, Michel Foucault, Paris: Flammarion, 1991, p. 218.

${ }^{9}$ Cf. Charles Soulié (dir.), Un Mythe à détruire? Origines et destin du Centre universitaire expérimental de Vincennes, Vincennes- Saint-Denis: Presses universitaires de Vincennes, 2012, p. 456 et 457.
} 
Vincennes instauraram uma espécie de mercado livre acadêmico, em que cada professor era colocado em concorrência com os demais na conquista da clientela estudantil.

Se no início Foucault parece acomodado à desordem de Vincennes experimentando, com seus amigos maoístas, os encantos da ação política direta num contexto às vezes quase insurrecional, rapidamente essa situação pesa sobre ele. Então, ele confidencia aos mais próximos que não suporta mais, durante as aulas, ser interpelado mais ou menos violentamente por seus interlocutores ${ }^{10}$. É preciso dizer que, no começo da experiência de Vincennes, era um esporte muito concorrido entre alguns militantes de extrema esquerda interpelar publicamente, e violentamente, os professores mais reputados sobre o seu posicionamento político, teórico ou outro. Ou, como se diz vulgarmente em francês, "pagar para ver". Era uma maneira, para eles, de lembrar o princípio de igualdade entre professor e aprendiz e, sobretudo, a preeminência do político sobre o intelectual. Em suma, o terrorismo político intelectual estava muito disseminado. Por exemplo, em filosofia, brigadas maoístas, lideradas notadamente por Alain Badiou, passavam em cada aula, a fim de verificar sua conformidade ideológica. Como resultado, alguns professores davam aula com um frio na barriga.

Nesse contexto, pode ser interessante lembrar que, antes de 68, Foucault tinha a reputação de ser um dos professores de filosofia da França que mais severamente avaliava os estudantes, e que, em meados dos anos 60, seu nome teria sido aventado pelo poder gaullista para atuar como subdiretor do Ensino Superior ${ }^{11}$. Sua virada à esquerda parece, portanto, ter sido um pouco tardia e ter sido favorecida especialmente pelos acontecimentos de maio de 68, que desempenharão um papel revelador para muitos filósofos franceses. De qualquer forma, Foucault permanece pouco tempo em Vincennes. Assim, e para retomar o título do artigo do Nouvel Observateur de 9 de fevereiro de 1970, dedicado à sua experiência em Vincennes, intitulado: “A Armadilha de Vincennes", Foucault deixa esse estabelecimento e vai para o Colégio de França. Ele delega a François Châtelet a tarefa de assumir a direção do Departamento e, sobretudo, a de assegurar a sua sobrevivência. Sobrevivência, pois em razão dos seus programas de ensino, assim como da validação demasiadamente liberal das disciplinas, esse

\footnotetext{
${ }^{10} \mathrm{Cf}$. Didier Éribon, Michel Foucault et ses contemporains, Paris: Fayard, 1994, p. 204.

${ }^{11}$ Cf. Didier Eribon, Michel Foucault, Paris: Flammarion, 1991, p. 158.
} 
Departamento perde seu reconhecimento nacional em 1970. Isso significa que seus diplomados não podem ensinar no ensino secundário, o que provoca uma queda no número de matrículas, pois o ensino era o principal espaço profissional de atuação para os formados em filosofia.

Nos anos seguintes a matrícula volta a aumentar um pouco, mas isso devido à abertura de Vincennes aos assalariados, aos não bacharéis, assim como aos estrangeiros, que eram numerosos na época, a ponto de compor quase a metade da clientela do Centro. Assim, seu público sofre grandes alterações. E, de certa maneira, ele não deixa de lembrar uma espécie de boemia tanto intelectual e artística quanto política. E é especialmente esta boemia parisiense, mais ou menos cosmopolita, que se proliferará muito no pós-68, com o advento do esquerdismo contracultural que sucede ao esquerdismo marxista, e que passará a fornecer sua base social à vanguarda proféticofilosófica de Vincennes em luta contra o stablishment acadêmico ${ }^{12}$.

\section{Uma trajetória}

Se alguns professores como Foucault, mas também Etienne Balibar, Michel Serres, ou ainda Jacques Lacan não suportam a desordem de Vincennes e, portanto, deixam esse estabelecimento rapidamente, outros o veem claramente como um lugar propício para o desenvolvimento de sua filosofia ${ }^{13}$. Este é, por exemplo, o caso de Deleuze, que, com sua “pop philosophie”, se tornará em seguida o ícone desse estabelecimento.

Assim, antes de evocar a pedagogia de Deleuze, é necessário descrever o personagem: e isto tanto no plano familiar, social e escolar quanto físico ${ }^{14}$. E, de fato, com esse filósofo, não estamos lidando com alguém que, graças à filiação a Spinoza, se interroga principalmente sobre "o que um corpo pode fazer?" 15 Corpo este que

\footnotetext{
${ }^{12}$ Cf. BOURDIEU, P. Homo academicus. Paris: Editions de Minuit, 1984.

${ }^{13}$ No que concerne à única conferência proferida por Jacques Lacan em Vincennes e às interrupções intempestivas ocorridas em 3 de dezembro de 1969 no Grande Anfiteatro de Vincennes, ver Jean-Michel Djian (dir.), Vincennes, une aventure de la pensée critique, Paris: Flammarion, 2009, p. 62 sqq.

${ }^{14}$ Aqui, minha fonte biográfica principal é a obra que Dosse dedicou a Deleuze e Guattari: Gilles Deleuze Félix Guattari, biographie croisée, Paris: La Découverte, 2007.

${ }^{15}$ Podemos assinalar aqui a existência do site intitulado: "A voz de Gilles Deleuze on line", hospedado no site da Universidade de Vincennes, que permite ouvir a voz de Deleuze (assim como de seu público) em aulas e ler em paralelo a transcrição das aulas dadas entre 1980 e 1986 [http://www2.univparis8.fr/deleuze/article.php3?id_article=137]. Do mesmo modo, podemos assinalar a existência do
} 
desempenha um papel essencial na relação pedagógica, uma vez que ele é o "médium” da mensagem. Mas o que me interessa aqui são sobretudo os desdobramentos sociais, íntimos, físicos, etc., do carisma de Deleuze.

Bem, aqui, e sem ceder ao fetichismo do "grande homem", penso que pode ser interessante apresentar duas fotografias deste filósofo, e isso sobretudo para estimular nossa sensibilidade, nosso inconsciente.

A primeira é uma das mais célebres do mestre. Nela se vê Deleuze presidindo uma cerimônia, como se fosse sagrada, no meio do seu público em Vincennes em 1975. Ou seja, três anos após publicar o "Anti-Édipo” com Guattari.

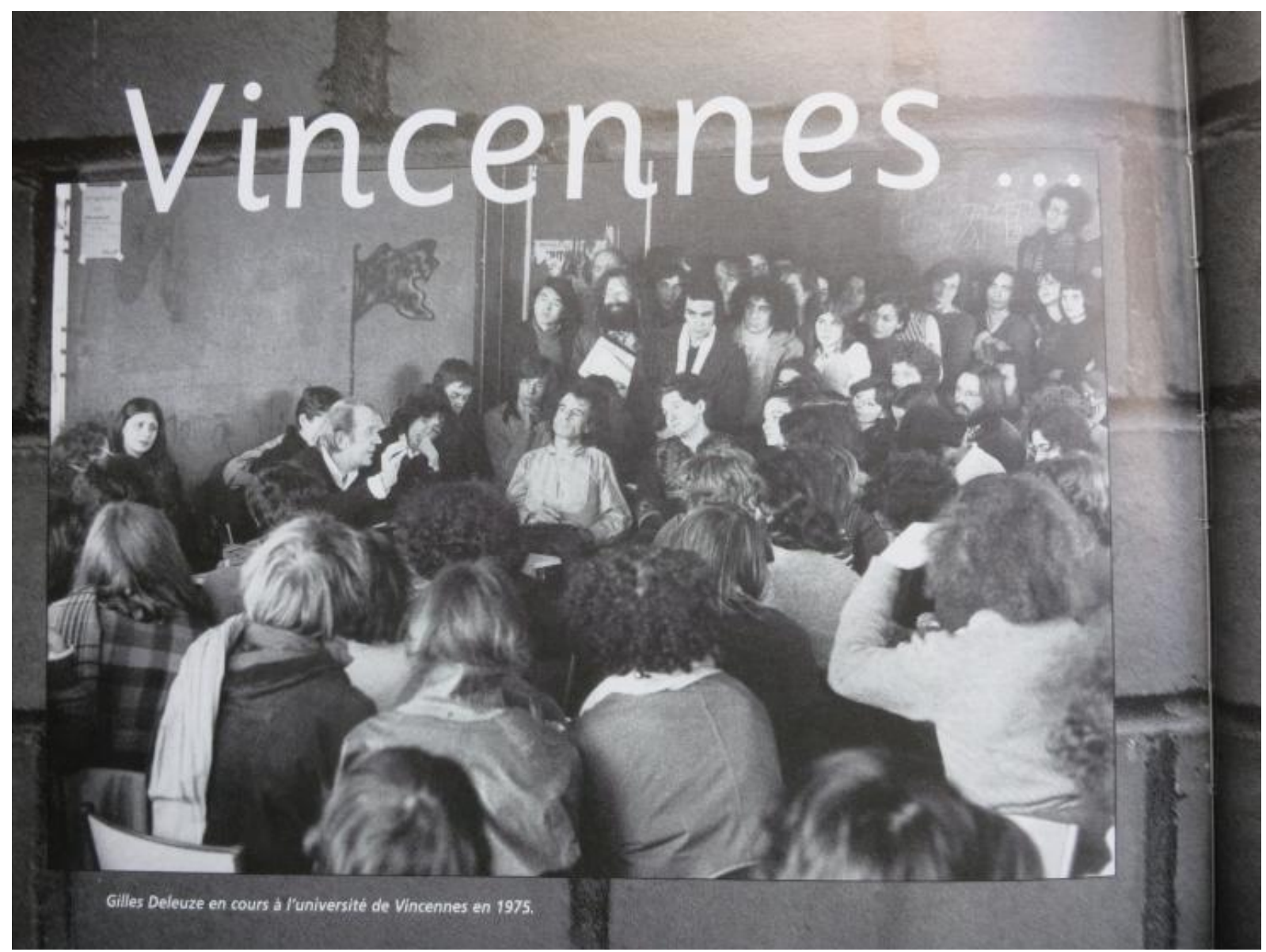

Fonte: Fotografia de H. Gloagen/Rapho. Reproduzida em: Le Siècle rebelle, Dictionnaire de la constestation au XXe siècle, Emmanuel de Waresquiel (dir.), Paris: Larousse, 1999, p. 626.

Abecedário de Gilles Deleuze, que reúne uma série de aulas filmadas de Deleuze, produzido e realizado por Pierre André Boutang. 


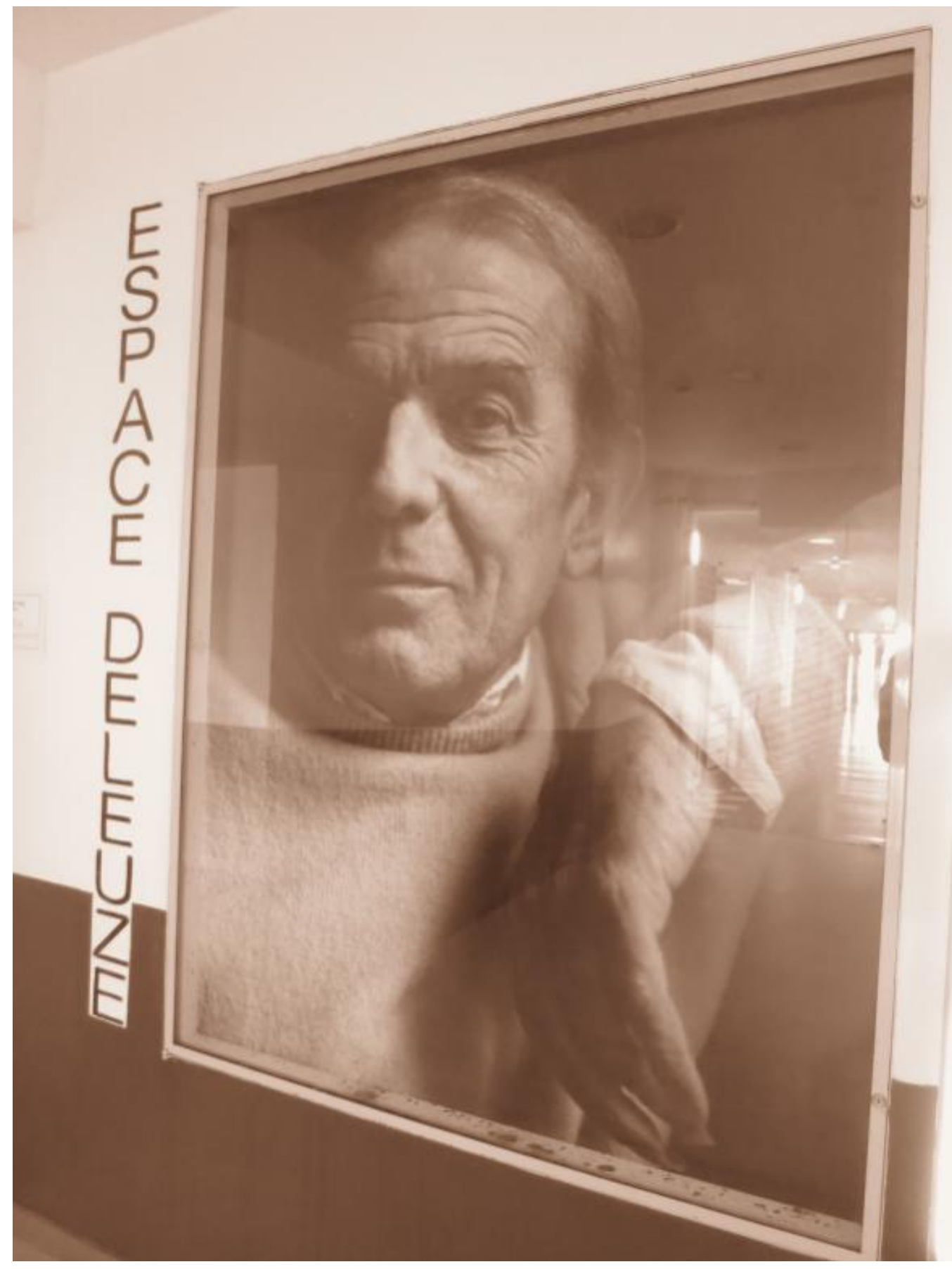

Fonte: Foto tirada pelo próprio autor em outubro de 2014.

A segunda é um retrato de Deleuze, provavelmente tirado em meados dos anos 80. Este retrato monumental está exposto na entrada do que se chama hoje de "Espaço Deleuze", na Universidade de Paris VIII. Trata-se de um complexo de salas muito chiques, cujo acesso é regulado por uma porta elétrica e onde são realizadas as reuniões do 
Conselho Universitário, as defesas de teses, etc. Em suma, é um lugar de pompa. Eu tirei esta fotografia em outubro de 2014.

Deleuze nasceu em Paris em 1925 e é o mais novo de uma família de dois filhos. Seu irmão mais velho, George, ingressa para a Grande Escola Militar Saint-Cyr a fim de se tornar oficial. Mas, durante a Segunda Guerra Mundial, ele se engaja na resistência, é preso pelos alemães e morre durante o seu envio para um campo de concentração. Claramente, os pais preferiam Georges, e o farão herói mártir. Por isso, Gilles, relegado à sombra de seu irmão, sofrerá muito ${ }^{16}$.

O pai de Deleuze é engenheiro e empresário, sua mãe é dona de casa. Todo verão sua família aluga uma casa à beira-mar em Deauville, o que denota um nível socioeconômico bastante elevado. De fato, os pais de Deleuze pertencem à burguesia de direita que execrava o governo da Frente Popular, e que, quando das primeiras férias remuneradas, assistirá com particular desgosto a chegada dos primeiros operários às praias da Normandia. Inversamente, Gilles - quetinha apenas 11 anos na época - ficaria encantado com esse acontecimento. Mais tarde ele diria que "Foi grandioso"

Após uma passagem pela khâgne ${ }^{18}$ do Liceu Louis le Grand, ou seja, pelo curso preparatório para as escolas normais superiores, Gilles Deleuze estuda filosofia na Sorbonne, conseguindo em seguida brilhantemente a "agregação"19 em 1948. Com efeito, desde muito cedo Deleuze se notabiliza pelas suas virtudes filosóficas. Assim, e como escreve seu biógrafo François Dosse, suas apresentações para o exame de admissão à Escola Normal que, apesar disso, ele não chegará a integrar, “já são consideradas como eventos aos quais não se deve faltar sob nenhum pretexto e capazes de mobilizar grandes públicos". Michel Tournier, seu companheiro de estudos desde 1943, enfatiza sua capacidade de - para falar como Max Weber - tirar da rotina a filosofia

\footnotetext{
${ }^{16} \mathrm{Cf}$. François Dosse, Gilles Deleuze Félix Guattari, op.cit, p. 112.

$17 \mathrm{Ibid}$, p. 113. Comparando Guattari e Deleuze no que concerne à relação com a política, Richard Pinhas escreve que para o primeiro "a política era bem mais que central e quase nativa. Deleuze, ao contrário, sempre me disse que tinha despertado para a política somente quando viu passarem as manifestações de Maio de 68 em Lyon. Isso faz sem dúvida com que ele seja um melhor pensador de Marx e da política do que os que nasceram dentro dela. Em todo caso, nas aulas, ele raramente falava dela. Às vezes, no início das aulas, para rir dois ou três minutos, mas nada mais". Cf. "Deleuze, le dehors entre les murs: entretien avec Richard Pinhas ", Europe, n 996, avril 2012, p. 191.

${ }^{18}$ As classes preparatórias (Khâgnes) preparam para o ingresso na Escola Normal Superior. Seus alunos são chamados de khâgneux. (N.T.)

${ }^{19}$ Do original "agrégation", concurso para atuar como professor de liceu ou de faculdade e que confere aos aprovados o título de professor agregado ("agrégé"). (N.T.)
} 
acadêmica: "Rapidamente tivemos medo dele pelo dom que tinha de nos pegar com uma palavra em flagrante delito de banalidade, disparate, frouxidão de pensamento. Poder de tradução, de transposição: toda a filosofia escolar ao passar por ele saía irreconhecível, com um ar de frescor, de nunca antes digerida, de amarga novidade, totalmente desnorteadora, repulsiva para a nossa fraqueza, nossa preguiça.”2o

Depois de ter lecionado no secundário e em cursos preparatórios, Deleuze tornase assistente na Sorbonne, em 1957, aos 32 anos. E imediatamente ele alcança "um sucesso espetacular" com os estudantes. Fato que, aliás, despertava ciúme em alguns dos seus colegas mais velhos com público claramente mais reduzido (Raymond Polin). Obviamente, desde essa época ele dispunha de certo carisma.

Em 1956, Deleuze faz um “bom casamento" "21. Na verdade, ele desposa religiosamente Fanny Grandjouan, filha de um grande empresário de Nantes, mais ou menos dandy ${ }^{22}$. Ela era colaboradora do grande estilista Balmain e também havia traduzido obras da literatura inglesa (D.-H Lawrence). Literatura cujo uso bastante consequente será feito por Deleuze ${ }^{23}$. Graças à esposa, Deleuze herda uma bela propriedade localizada na região de Limousin em Saint Léonard de Noblat. Assim, e como escreve um dos seus biógrafos, foi nesse "edifício, com vista para os prados e para as colinas arborizadas ao longe, nesse terraço, ou nesse parque, cuidadosamente mantido pelo seu jardineiro, que ele escreveu uma parte considerável de suas obras". ${ }^{24}$

\footnotetext{
${ }^{20}$ Cf. Michel Tournier, Le vent Paraclet, Paris: Gallimard, 1977, p. 155.

${ }^{21}$ Nessa ocasião Deleuze escreve ao seu orientador de tese, Maurice de Gandillac: "Foi uma bela festa. $O$ casamento é um estado esplendoroso, está na hora de eu saber disso." Cf. F. Dosse, op.cit, p. 133.

${ }^{22}$ Citação possível sobre a sua euforia em relação ao casamento, ou seja, maneiras elegantes, refinamento, atitude moral. (N.T.)

${ }^{23}$ Cf. Gilles Deleuze et Claire Parnet, "De la supériorité de la littérature anglaise-américaine", in Dialogues, Flammarion, 1977.

${ }^{24}$ Cf. Yannick Beaubatie, "Grandeur de Gilles Deleuze », in Y. Beaubatie (dir.), Tombeau de Gilles Deleuze, Mille Sources, 2000, p. 12.
} 


\section{"A voz de seu mestre" em Vincennes ${ }^{25}$}

Muitos de seus contemporâneos assinalam que Deleuze se vestia geralmente com muito gosto. E o tom de sua voz era, ao que parece, mais ou menos afetado. Assim, seu biógrafo relata que nos anos 50 ele chega a ser tratado como "gay", ou seja, homossexual, por um aluno do liceu. Ao que ele responderá com elegância: "Sim, e daí?" Igualmente, seu chapéu "que se tornou lendário", bem como suas unhas bem desenvolvidas, suscitarão comentários, mais ou menos acerbos, relativos ao seu "dandismo" ${ }^{26}$. De constituição física frágil, ele sofreria muito cedo de graves problemas respiratórios (asma). Assim, a partir de 1969, e após uma toracoplastia, passará a contar com apenas um pulmão, o que o obrigava a falar suavemente, assim como a se mover lentamente: “'Não tenho mais pulmões', dizia ele com um riso que vinha do fundo da garganta." 27

No entanto, muitos testemunhos destacam o charme, quase hipnotizante, de sua voz rouca e ao mesmo tempo doce. Tanto é que, em 2005, Claude Jaeglé publica um livro intitulado: Portrait oratoire de Gilles Deleuze aux yeux jaunes [retrato oratório de Gilles Deleuze com os olhos amarelos] ${ }^{28}$. Obra em ele escreve: "Esta voz é um charme, um canto eficaz e a expressão pessoal de um bon vivant. Seu poder mágico nos faz querer lhe dar razão antes mesmo de saber se ele tem razão". ${ }^{29}$ Quanto a André Bernold, que era manifestamente sensível ao aristocratismo de Deleuze, chega a escrever: "Ele foi um dos mais importantes oradores do seu tempo, e o maior de todos os que tinham por profissão ensinar filosofia. Ele era compreendido somente por poucos. Ele foi perseguido: foi objeto de uma inveja que jamais o embaraçou. Ele desprezava essas misérias, por causa da alegria de sua vida, que era a de filosofar. De um temperamento altivo, ele só suportava o povo. Mas sua ironia era formidável. Sua voz era das mais extraordinárias. Athénée a compara a uma

\footnotetext{
${ }^{25}$ Esta reflexão se inspira sobretudo em Isabelle Kalinowski: "La voix de Max Weber et le charisme professoral”. In Leçons wébériennes sur la science et la propagande, obra reproduzida a seguir pela tradução de La Science, profession et vocation de Max Weber, Agone, 2005.

${ }^{26}$ Por exemplo, em 1973 Michel Cressole publica uma obra sobre Deleuze na qual escreve: "Teu casacão preto de operário é o equivalente de teu casacão rosa ou do casaco plissado de Maryline Monroe, e tuas unhas longas, equivalem aos óculos pretos da Greta Garbo. Deleuze-Minelli vai ver como isso funciona para o AntiÉdipo e para você, tu poderás então, superstar, mudar tua foto dedicada a milhares de outras, perseguidores $e$ perseguidoras, homossexuais, loucos, Sartre, situacionistas, drogados, neonazistas e vendedores de pequenas Torres Eiffel musicais em plástico." Cf. Deleuze, Paris: Ed. Universitaires, 1973, p. 105.

${ }^{27}$ Y. Beaubatie (dir.), op.cit, p. 14.

${ }^{28}$ Portrait oratoire de Gilles Deleuze aux yeux jaunes, Presses universitaires de France, 2005.

${ }^{29}$ Cf. C. Jaeglé, op.cit, p. 33.
} 
grosa, a uma torrente de pedras. A elocução era de uma extrema distinção, um pouco lassa, a dicção lenta e doce. Apollodore compara sua voz a de um feiticeiro. Era um homem de uma perfeita nobreza, que tinha horror a tudo o que diminui." 30

Assim, Deleuze "enfeitiça” seu público, com "a sonoridade" de sua voz - como ressalta esse comentarista -, pelo seu poder de contágio imediato que age sempre de forma mais intensa do que "o visual". Voz sobre a qual podemos perguntar se com a vestimenta, a hexis corporal, etc., que a acompanham, não condensa, mas sob uma forma sensível e estilizada e, portanto, potencialmente e particularmente persuasiva, toda uma trajetória social e escolar ${ }^{31}$. Mas também toda uma relação com o mundo acadêmico, intelectual, e, de modo mais geral, com a ordem social e política, suscetível de entreter, ou não, de modo pré-reflexivo, a adesão, a identificação, e mesmo a "entrega de si", mais ou menos inconsciente, de seu público ${ }^{32}$, suscetível, por essa razão, de desencadear vocações ${ }^{33}$. Sabendo que o fato de saber suscitar vocações e, portanto, de trabalhar para a reprodução do corpo mas na sua mais sublime e nobre dimensão, é geralmente considerado como um dos pináculos da arte pedagógica.

Neste momento, desejo evocar a etimologia da palavra "vocação". Na verdade, ela remete a "vocatio", do latim, que designa a ação de “chamar", mas também, fato curioso, de "acusar na justiça”, assim como de "convidar". Significado que também é encontrado na palavra alemã "Beruf”, que, lembro, ocupa um lugar importantíssimo na sociologia das religiões de Max Weber. De fato, tudo se passa como se a voz fosse um dos principais médiuns da vocação ${ }^{34}$. E como se um dos desdobramentos mais profundos

\footnotetext{
${ }^{30}$ Cf. « Suidas », Philosophie, n 47, septembre 1995, p. 8.

${ }^{31}$ Nota-se assim que em razão das liberdades que se autoriza ao oral, dado seu caráter mais familiar ligado sobretudo ao sentimento de proximidade, entre si, das interações que ele gera, etc., assim como das necessidades pedagógicas visando principalmente a se fazer compreender por um auditório mais ou menos compósito, um curso é frequentemente menos censurado do que a publicação que dele resulta. E, então, ele compreende muitas repetições, cortes, avaliações implícitas, apartes, traços de humor e de ironia, etc., os quais desaparecem no texto escrito, embora exerçam um papel essencial na orientação assim como na formação dos estudantes, por exemplo, através da transmissão de um panteão de autores hierarquizados. Por analogia, pode-se pensar na importância das didascálias no teatro, ou seja, das instruções orais dadas aos intérpretes.

${ }^{32}$ Aqui, poder-se-ia contornar sociologicamente a intuição de McLuhan, segundo a qual: “A mensagem é o médium".

${ }^{33}$ A voz tornando-se então (a exemplo da beleza) o veículo de uma "promessa", ou seja, de um futuro mais ou menos indeterminado, mas, particularmente, exaltante, segundo o testemunho dos interessados.

34 Precisando o contexto de aplicação da fórmula medieval segundo a qual "não há mestre sem mestre ", pode-se perguntar se a copresença física entre mestre e discípulo não é necessária à produção e à vocação. Assim, Pierre Bourdieu assinala que alguns atos/ritos de instituição têm absoluta necessidade da presença
} 
do profetismo residisse no carisma da voz, que, como se verá na sequência, é um composto paradoxal e, sem dúvida, relativamente instável de coerção e de sedução ${ }^{35}$.

A este propósito, gostaria de relatar um novo excerto de Jaeglé. Com efeito, ele escreve que a dicção do conceito por Deleuze, ou mais precisamente sua "vocalização", leva o público a "uma espécie de transe, que é como o inverso do movimento do subjetivo em ação no ápice da inspiração que se liberta ao mesmo tempo no lado do filósofo. O público é um para-raios. Cabe a ele acumular e depois converter a energia recebida em algo inteligível". ${ }^{36}$

De fato, quando se lê os biógrafos de Deleuze, não se consegue deixar de se impressionar com a importância atribuída ao corpo, à voz, assim como ao afeto na relação com o seu público ${ }^{37}$. E isso até mesmo enquanto ele preparava suas aulas com muito cuidado, chegando a ensaiá-las, a fim de ter "momentos de inspiração." ${ }^{38}$ Assim, Deleuze ressalta que durante uma aula, o que primeiramente capta, interessa aos estudantes é a emoção; e que uma aula é tanto emoção quanto inteligência. $E$ que, com frequência, é a percepção, o afeto, cujo corpo e a voz são os médiuns privilegiados; é por meio deles que os estudantes começam a entrar na disciplina filosófica.

E é principalmente através de suas aulas que Deleuze diz ter compreendido a que ponto a filosofia precisa não somente de uma compreensão filosófica dos conceitos tal

\footnotetext{
física das pessoas envolvidas. E portanto seria impossível procedê-los na presença simplesmente da efígie das pessoas envolvidas.

35 Segundo a tipologia religiosa de Max Weber, se estaria portanto entre a magia, que ele define sobretudo pala «imposição » de Deus, e da religião, e que vem sobretudo da « veneração » de Deus. Cf. Max Weber, Sociologie de la religion, traduction d'Isabelle Kalinowski, Paris: Flammarion, 2006, p. 124.

${ }^{36}$ C. Jaeglé, op.cit, p. 84 .

37 Isso explica talvez porque, apesar da abundância do seu público, Deleuze sempre tenha recusado ensinar em anfiteatro (coisa que Lacan, por exemplo, fará sem problema). É como se ele tivesse necessidade de manter certa proximidade física com esse público - o qual ele não queria que se transformasse numa massa anônima - proximidade esta talvez em parte ligada a suas fragilidades pulmonares. Com que proximidade se combina aliás perfeitamente, como se verá agora, uma certa distância tanto intelectual quanto social. Além disso, esse composto paradoxal de proximidade/distância parece ser um ingrediente estrutural de todo poder carismático. Ele explica por exemplo essas alternâncias de "calor", "frio", experimentadas pelos "discípulos" em seus contatos com o "mestre" objeto de uma forte transferência e ao mesmo tempo tabu, porque sagrado, e portanto separado. Vivência e comportamento contraditórios que, do ponto de vista do mestre, são frequentemente atribuídos à "irracionalidade" ou à falta de "maturidade" suposta dos discípulos.

38 "Um corpo se prepara enormemente, a fim de ter momentos de inspiração. Eu me preparava muito para um momento de inspiração. (...) Uma aula é como o teatro, ou a música, a gente ensaia. E se não se está bem preparado, não há inspiração." Assim no fim de sua vida, e sentindo a inspiração deixá-lo, Deleuze decide parar com as aulas e dedicar-se essencialmente a seus escritos. Sobre este ponto, ver no Abecedário o que ele diz sobre a palavra "professor".
} 
como se pode desenvolver, e mesmo exacerbar, especialmente na escola ou na universidade, ao atuar sobre esses eleitos/condenados do sistema que são os "bons alunos", eles mesmos muitas vezes destinados a se tornar futuros professores. Isso sem dúvida alimenta uma forma de fechamento da instituição sobre si mesma, seja do ponto de "vista escolástico", mas também de uma compreensão não filosófica, ou seja, por meio de percepções e afetos. Por exemplo, do tipo daquela que mobilizam espontaneamente os profanos, a priori estrangeiros ao universo filosófico, ou até mesmo acadêmico. Isso leva Deleuze a desenvolver uma teoria da dupla compreensão.

Eis o que ele escreve:

Precisamos das duas. A filosofia está numa relação essencial e positiva com a não filosofia: ela se destina diretamente aos não filósofos. Tomemos o caso mais surpreendente, Spinoza: é o filósofo absoluto, e a 'Ética' é o grande livro do conceito. Mas ao mesmo tempo o filósofo mais puro é aquele que se dirige estritamente a todo o mundo: qualquer um pode ler a 'Ética'se se deixar conduzir por esse vento, esse fogo. Ou Nietzsche. Nele há ao contrário um excesso de saber que mata o vivente na filosofia. A compreensão não filosófica não é insuficiente ou provisória, ela é uma das duas metades, uma das duas asas." ${ }^{39}$ Assim, e apesar de seu "aparelho conceitual sistemático e erudito", esse filósofo pode possibilitar um encontro imediato e sem preparação, assim como um não filósofo, ou ainda alguém desprovido de toda cultura, podendo provocar uma súbita iluminação, uma 'flama'. ${ }^{40}$

Assim, para Deleuze, não existem duas filosofias: ou seja, uma "conceitual" reservada aos profissionais, e outra reservada ao público e que falaria a todos. Como a pintura ou, melhor ainda, a música ${ }^{41}$, a filosofia se dirige a todos, independentemente do seu nível de educação ou formação prévia. Assim, diz ele, Beethoven fazia música para todos, ou seja, se dirigia tanto a músicos quanto a não músicos. Ele não produzia um “Beethoven mais simples" para os últimos. Decorre daí a profunda indiferença de

\footnotetext{
${ }^{39}$ Deleuze, Pourparlers, Paris: Minuit, 1990, p. 190.

${ }^{40}$ Spinoza philosophie pratique, Paris: Minuit, 1981, p. 173 e seguintes.

${ }^{41}$ No Abecedário e na palavra professor, Deleuze diz que: «As aulas são uma espécie de Sprechgesang [estilo de canto declamado e modulado após entonações da palavra, utilizado por compositores vienenses. N.T.], mais próximas da música do que do teatro." Em 1972, Deleuze registra 45 voltas com Richard Pinhas, então com 21 anos e que era músico e violinista profissional (música experimental e rock eletrônico). Disco intitulado Le voyageur/Torcol e no qual Deleuze declama, "com sua voz tão particular ", o aforismo 638 da obra de Nietzsche Humain trop humain com um acompanhamento rock do grupo Schizo. Cf. http://radioradiodeleuze.blogspot.fr/2009_12_01_archive.html
} 
Deleuze, assim como de seus colegas do Departamento de Filosofia em relação às questões de "nível dos estudantes". Destarte, em Vincennes, todas as aulas de filosofia eram abertas a todos os alunos. Portanto, os calouros frequentavam os mesmos cursos que os estudantes de doutorado ${ }^{42}$. Da mesma maneira, Deleuze não via nenhuma diferença de natureza entre suas aulas no liceu e na universidade.

Quando dava aula, Deleuze solicitava o afeto ou a sensibilidade de seu público, o que, aliás, não significava mobilizar a perspectiva artística. Isso traduz muito bem a visão que ele tinha de seu público. Assim, a esse propósito, gostaria de apresentar um novo excerto da obra de Jaeglé: “Acrescentemos esse conselho que o professor, 'meio figo meio uva'43, dá aos estudantes que se apressam para tomar a palavra, no final de seu seminário sobre Spinoza: 'Nada de teoria. Sentimento, hein!' - fala que manifesta o mal presságio de um filósofo que lamenta a ingenuidade daqueles que especulam a teoria apenas a partir da teoria. Não, é inútil recorrer ao propósito filosófico se não for a partir da intensidade que lhes transporta, da veemência que lhes inspira. Durante as objeções intermináveis dos participantes do seminário, o filósofo dominante esfrega as unhas para passar o tempo e resmunga algumas respostas tolerantes por puro ritual pedagógico. Basta ouvir o tom afável e desenvolto com o qual Deleuze trata seus interlocutores para perceber a indiferença de sua atenção. A seus olhos, as objeções são vazias e as discussões inúteis." 44

\section{Um profeta muito magistral}

Bom, aqui, quero enfatizar um paradoxo (dentre outros...). Na verdade, ainda se está na Vincennes dos anos 70, ou seja, naquela em que o espírito antiautoritário e antihierárquico é elevado ao seu máximo. E aqui um admirador de Deleuze descreve a figura do mestre na sua majestade, o qual adere com todas as suas fibras ao dispositivo pedagógico por mais tradicional que seja: o da aula magna ${ }^{45}$.

\footnotetext{
${ }^{42}$ Cf. François Châtelet, "Disparité et non hiérarchie », in Vincennes ou le désir d'apprendre, Jacqueline Brunet (dir.), éd Alain Moreau, 1979, p. 126 e seguintes.

43 Do original, "mi-figue mi-raisin”, significando que há uma ambiguidade, uma mistura de satisfação e de descontentamento, de seriedade e de prazer. (N.T.)

${ }^{44}$ C. Jaeglé, op.cit, p. 17.

${ }^{45}$ Descrevendo o personagem Deleuze em Vincennes, Bruno Tessarech fala de um homem que, «ao passar,
} 
Assim, o ensino de Deleuze terá sempre um caráter muito magistral, forma que ele reivindicará aliás até $\mathrm{o} \mathrm{fim}^{46}$. De fato, para ele há dois tipos de aulas. Aquelas que demandam interrupções, questões imediatas. E aquelas em que somente se interrompem "palavras" ou aquilo que, com um pouco de desdém, ele chama de "discurso". E aquelas “em que há um senhor que fala”. Deleuze fará somente aulas magnas, "porque, diz ele, é como a música, e não se interrompe a música." 47

Com isso, Deleuze tinha horror ao que ele chamava de "discussões”. Pois, para ele, “a filosofia não tem nada a ver com uma discussão, já é muito difícil compreender que problema alguém coloca e como o coloca, é preciso simplesmente enriquecê-lo, variar as condições, acrescentar, concordar, jamais discutir." ${ }^{48}$ E é por isso, aliás, que ele faz tão pouco caso das objeções, das perguntas que lhe são feitas nas aulas. Certamente, ele as escuta com muita educação e cortesia, o que nele talvez remeta a uma forma de tato social que tinha a ver com sua trajetória. Com efeito, Deleuze nunca afrontou ninguém, e suas objeções, à imagem dos seus inícios de aulas, eram sempre apresentadas no modo interrogativo ou duvidoso. Mas ele jamais respondia às perguntas e objeções. Pois, para ele, “o objetivo não é responder a perguntas, mas sair, sair-se bem." 49

pelos corredores, provocava silêncio e nesses momentos, cercado de discípulos e de confrades, me parecia ao mesmo tempo próximo e inacessível, como um personagem de pintura antiga instalado em sua majestade. " Ele acrescenta ainda um pouco adiante: « ao seu contato descobríamos a força de toda transmissão intelectual: o respeito por um mestre que se admira. » Cf. Vincennes, Paris: Nil éditions, 2011, p. 31-32.

${ }^{46}$ Sobre este ponto, ver o que diz Deleuze no seu Abecedário sobre a palavra "Professor". Cf. L'Abécédaire de Gilles Deleuze, filme realizado por Pierre-André Boutang, Éditions du Montparnasse, 2004. Os excertos provêm desta entrevista.

${ }^{47}$ Quanto ao paralelo entre música e filosofia, Deleuze chega a escrever que « os conceitos são exatamente como sons, cores ou imagens, são intensidades que convêm ou não, que passam ou não passam. » Cf. G. Deleuze, C. Parnet, op.cit, p. 10.

${ }^{48}$ Gilles Deleuze, Pourparlers, p. 125. A tese será retomada em seguida: «Todo filósofo foge quando escuta a frase: a gente vai discutir um pouco. As discussões são boas para as mesas redondas, mas é sobre uma outra mesa que a filosofia joga seus dados cifrados. As discussões, o mínimo que se pode dizer delas é que não farão avançar o trabalho, pois os interlocutores jamais falam da mesma coisa. "E, de fato sublinham os autores, «jamais se está sobre o mesmo plano ». Cf. G. Deleuze, F. Guattari, Paris: Minuit, Qu'est-ce que la philosophie ?, 1991, p. 33.

${ }^{49}$ Cf. G. Deleuze, C. Parnet, op.cit, p. 7. 


\section{Enfrentar, mas com serenidade}

Durante os anos 70, Deleuze precisará de todo seu tato para enfrentar, com diplomacia, o terrorismo político intelectual de alguns grupos de estudantes/professores que se erigiam em tribunal popular ambulante, como nas intervenções, mais ou menos intempestivas e inspiradas, de marginais, borderlina de todo tipo, até mesmo os esquizos, que haviam encontrado refúgio nesse lugar particularmente hospitaleiro que era Vincennes e que alguns, aliás, não hesitavam em comparar com um vasto "hospital de dia" funcionando tanto em benefício dos estudantes quanto dos professores. Em sua homenagem a Gilles Deleuze, Philippe Mengue relata o estilo de algumas dessas intervenções de caráter político:

«Deleuze! A gente veio para esclarecer o que se passa aqui, com todas essas pessoas agrupadas em torno de você, que te veneram como um mestre! Justifique tua prática docente! ", lançavam eles, de um lado, armando-se das Considerações intempestivas de Nietzsche.

«Deleuze! Tua filosofia é somente a última ideologia do capitalismo agonizante! », lançavam eles, de outro lado, gritando O Capital ou O Pequeno livro vermelho.

Silêncio constrangedor na assistência, de alguns, gozação, de outros. Sorriso no canto da boca, Deleuze replicava com a maior calma do mundo, num tom meio-meditativo, meio-interrogativo:

«Sim... Sim..., é bem importuno o que você me disse! Porque, veja, eu tento fazer o contrário... ! » E com prudência, sem se defender de primeira, e sempre com respeito pelo seu interlocutor, ele ia livrando pouco apouco, sem violência, o espaço de pensamento que permitia melhor examinar essas questões e esses julgamentos. " ${ }^{50}$

Se Deleuze não acreditava nas discussões, ele ao contrário acreditava muito nos "efeitos retardados", ou seja, no fato de que não se entende na hora, mas depois. Isso está aliás de acordo com sua teoria da dupla recepção segundo a qual, na maioria das vezes, o afeto precede ao conceito. De fato, no contexto da aula magna, tal como a concebe Deleuze, não há nada para discutir. Em vez disso, deve-se sentir: isto é, se deixar levar, numa palavra, se abrir - ou não - à intensidade que nos é proposta/imposta pelo professor. E eventualmente variar, embelezar. Ou, como resume um dos seus

\footnotetext{
50 «En hommage à Gilles Deleuze: Vincennes, une voix, un personnage proustien... », in Y. Beaubatie, op.cit, p. 51-52.
} 
comentadores: "Escute! Isso pensa em mim, e se isso capta você, isso vai fazer pensar em você." 51

Mas sobretudo, Deleuze acredita muito nos « encontros », ou seja, numa forma de eleição recíproca entre o que é preciso chamar aqui de mestre e seus discípulos. E como os encontros amorosos, ou «coups de foudre $e^{52}$ ", estes têm algo de total. Ou seja, eles misturam tanto o intelectual quanto o afetivo e o carnal, o que lhes dá, aliás, um gosto de verdade muito pronunciado, às vezes cheio de confusões. E esses encontros que também podem acontecer - e talvez sobretudo - com "as coisas", por exemplo, com um quadro, uma música ou um filme, interessam muito ao filósofo empirista, pragmatista e vitalista, que era ele: pois esses são "canalizadores de problemas" que forçam a pensar"

Os encontros forçam a pensar, pois são choques que criam uma relação enfim concreta, ativa, e não mais escolar, formal ou emprestada, com o pensamento. Ou como escreve Deleuze : «O pensamento não é nada sem algo que force a pensar, que faça violência ao pensamento. Mais importante que o pensamento, há o que "leva a pensar"; mais importante que o filósofo, o poeta (...) Le leitmotiv du Temps reencontrado, é a palavra forçar: impressões que nos forçam a olhar, encontros que nos forçam a interpretar, expressões que nos forçam a pensar. " ${ }^{54} \mathrm{E}$ isso porque: «Uma obra de arte vale mais que uma obra filosófica; pois o que é envelopado no signo é mais profundo do que todas as significações explícitas. O que nos violenta é mais rico que todos os frutos da nossa boa vontade ou do nosso trabalho atendo; e mais importante do que o pensamento, há "o que leva a pensar ». ${ }^{55}$

\footnotetext{
${ }^{51}$ Cf. Sébastien Charbonnier, Deleuze pédagogue, la fonction transcendantale de l'apprentissage et du problème, l'Harmattan, 2009, p. 177. Deleuze, ao mobilizar na sua filosofia, assim como na sua pedagogia, um «método de dramatização » que consistia em por em cena «personagens conceituais » em julho de 2012, e no quadro do Festival de Avignon, é interpretado por Robert Cantarella que monta uma peça intitulada Faire le Gilles e na qual o autor, ligado pelas suas orelhas a um curso de Deleuze, imita-o seguindo escrupulosamente as entonações, inflexões, silêncios, assim como o ritmo da palavra do mestre. Em 2014/2015, e após tê-lo reapresentado na Ménagerie de verre em Paris, R. Cantarella reedita a experiência na Cinémathèque française, apresentando em voz as aulas de Deleuze sobre o cinema.

52 Paixão instantânea e avassaladora. (N.T.)

53 S. Charbonnier, citado por S. Charbonnier, op.cit, p. 74.

${ }^{54}$ G. Deleuze, Proust et les signes, Paris: PUF, 1970, p.40.

${ }^{55}$ G. Deleuze, Proust et les signes, Paris: PUF, 1964, p. 41. Isso vai ao encontro da ideia leibniziana mencionada sobretudo por Charbonnier, segundo a qual: "Não formamos nossas ideias porque queremos; elas se formam em nós, elas se formam para nós, não como consequência da nossa vontade, mas seguindo nossa natureza e a das coisas. » Cf. Leibniz, Essais de théodicée, Paris: Flammarion, 1969, §403.
} 
Assim, compreende-se melhor o primado acordado à experiência estética de Deleuze, tanto em sua teoria do conhecimento quanto em sua prática pedagógica, ou sua ligação visceral com a forma da aula magna mas na sua versão profética, ou seja, potencialmente performativa ${ }^{56}$. Na verdade, e como escreve S. Charbonnier, ao «levar a pensar » esse tipo de curso provoca entre os ouvintes um desequilíbrio do pensamento e « a multiplicação de ramificações inconscientes » que produzem a energia individual para pensar. E, em contrapartida, essas “ramificações" permitem ao filósofo recarregar-se ${ }^{57}$. Esboça-se então uma forma de troca, certamente desigual mas de qualquer maneira uma troca, entre o profeta e seu público, e que os contemporâneos/comentadores de Deleuze descrevem frequentemente mobilizando metáforas físicas emprestadas tanto da filosofia quanto do vocabulário mágico-religioso.

\section{Os patrocinadores do profeta}

Deleuze mantém, portanto, uma relação singular com seu público. E mais especificamente com o público de Vincennes, que ele considerava ser "o esplendor de Vincennes" ${ }^{58}$. Isso leva a se interrogar sobre as condições sociais, escolares, etc., de possibilidade desta felicidade pedagógica.

$E$, de fato, quais eram os interesses de ambas as partes? Que interesse tinha esse público, a priori rebelde, em se submeter assim a esse mestre? E, reciprocamente, qual o interesse desse mestre nesse público? Então, ao se olhar pelo lado do público, pode-se dizer sem dúvida que ele encontrará em Deleuze um formidável intérprete dos humores anti-institucionais do momento, aspecto que ele saberá expressar, sem se alienar ou se reduzir. Pois, Deleuze estava profundamente em sintonia com as expectativas de seu público. E aqui se pode citar o testemunho encantado de E. Roudinesco: “Exaltado, mas sempre tolerante, Deleuze foi o filósofo mais socrático que se pode imaginar. Longe de

\footnotetext{
${ }^{56}$ Descrevendo a figura do anti-pedagogo dedutível tanto da filosofia como da prática pedagógica de Deleuze, Giles Boudinet escreve: «O anti-pedagogo seria por si um artista, um saltimbanco, um músico nômade para ser acompanhado e ele mesmo acompanhante em caminhos de bifurcação constante que ele não cessa de abrir. Sua síntese é « disjuntiva ». Cf. Deleuze et l'anti-pédagogie, Paris: l'Harmattan, 2012, p. 140.

${ }^{57}$ S. Charbonnier, op.cit, p. 50.

${ }^{58}$ Abecedário. Citação também possível.
} 
fazer-se o ídolo de um culto religioso, ele fascinava seu público, tornando-se o parteiro suave e bárbaro do desejo daqueles que vinham ouvi-lo." 59

E assim, compreende-se melhor a afinidade profunda que une a "filosofia do desejo" de Deleuze com a experiência pedagógica de Vincennes como um mercado livre acadêmico, em que cada professor é colocado em concorrência carismática com todos os outros na conquista da clientela estudantil. Assim, Deleuze explica bem como ele se nutria da diversidade de seu público, e notadamente de seu caráter fora da norma, a fim de produzir uma filosofia conforme ao espírito dos lugares, tentando escapar da labuta da instituição filosófica.

De fato, eu penso que na divisão do trabalho instaurada por Deleuze, o filósofo é aquele que - de acordo com a sua definição da filosofia - produz conceitos ${ }^{60}$, ou seja, esse trabalho de dar forma conceitual a um material sensível, que, em grande parte, vem de seu público: ou, como ele disse no seu linguajar, "vem de fora" ${ }^{61}$. E notar-se-á que essa divisão do trabalho é afinal de contas muito tradicional; ela não deixa esquecer a oposição matéria/forme, desenvolvida sobretudo por Aristóteles, ou ainda o tratamento que Platão reserva aos poetas.

Consequentemente, o público de Deleuze era particularmente disparate, o que, de alguma forma, fará dele um filósofo exotérico e também contribuirá para o seu distanciamento pela instituição. De fato, em grande parte, ele era exterior à filosofia. E aqui já se pode pensar no vasto contingente de estudantes de artes, música, cinema, etc., disciplinas em vias de cristalização institucional, e que farão um uso particularmente "liberado" de sua filosofia, assim como da filosofia em geral. Aspecto este bem visível quando se lê, por exemplo, suas teses de doutorado. De fato, pode-se dizer que, com sua “filosofia pop”, Deleuze promoverá uma forma de uso artístico da filosofia, e de modo mais amplo, da linguagem conceitual, ou seja, emancipada das restrições acadêmicas

\footnotetext{
${ }^{59}$ Cf. Charles Soulié (dir), Un Mythe à détruire?, op. cit, p. 219.

${ }^{60}$ Cf. O que é filosofia? Com Guattari, Paris: Minuit, 1991.

${ }^{61}$ Cf. Anti-Édipo. Diz-se em termos spinosistas: "Quando encontramos um corpo exterior que não está de acordo com o nosso, tudo se passa como se a potência desse corpo se opusesse à nossa potência, operando uma subtração: diz-se que nossa potência de agir é diminuída e que as paixões correspondentes são de tristeza. Ao contrário, quando encontramos um corpo que está de acordo com a nossa natureza, dirse-á que nossa potência adiciona-se à outra: as paixões que nos afetam são de alegria, nossa potência é aumentada ou ajudada."
} 
comuns ligadas sobretudo à reprodução do corpo dos filósofos profissionais. E por isso, aliás, os artistas lhe serão gratos.

\begin{abstract}
A tropa dos fiéis
Descrevendo a «flora multicores » da Vincennes do início dos anos 70, Philippe Mengue, futuro agregado, doutor de Estado e professor na Universidade de Aix de Marselha, e que antes de chegar à Vincennes tinha feito uma "formação muito clássica » na Sorbonne onde lhe falaram somente de obras de história da filosofia e da filosofia de Deleuze, mas jamais de "Diferença e repetição" ou de "Lógica do sentido", o que contribuiria sem dúvida, em parte, para um sentimento (relativo) de exclusão de Vincennes, escreve: "A tropa dos fiéis era composta por pessoas vindas de todos os horizontes e de todas as disciplinas (filosofia, médicos psiquiatras, músicos, cineastas, artistas, militantes políticos...). Havia também belas jovens, de elegância natural, desenvoltura e refinamento espontaneamente negligenciado, para dizer tudo, extremamente parisienses. Todos esses seres e essas jovens me pareciam encarnar um mundo no qual eu me sentia em parte excluído. Junto a eles, quando eu os cotovelava - cores da faculdade, reunião, A.G, aulas... - eu me sentia meio esquerda e desajeitado, sem saber muito o porque. 0 que eles representavam então para me impressionar tanto? Tudo. Tudo ao mesmo tempo, para o meu pânico: mundo da sedução e da paquera assim como mundo da inteligência e da criação, da juventude e da beleza, da distinção e do refinamento intelectual, do gosto. Numa palavra, esses meios de Vincennes, ressuscitavam, a sua maneira, os antigos salóes, tanto os aristocratas, de Paris de Marcel Proust, quanto esses dos vivos, espirituais e revolucionários do Século das Luzes, ou, ao menos, eles compunham um perfume primaveril que anunciava novidades radicais! Eu ocupava, para falar a verdade, uma posição muito instável, pressionado como eu estava entre esses dois sentidos opostos. Pois, pelo meu passado e meus estudos, eu estava suficientemente próximo desse mundos para ser atraído ou ficar intrigado, mas, não sei porque razão, insuficientemente próximo para me sentir à vontade e solidário. " ${ }^{62}$
\end{abstract}

Ainda sobre o caráter disparatado do público de Vincennes, pode-se também pensar nos estrangeiros, muito numeros em Vincennes, e que farão valer logo depois o seu capital filosófico francês em outros mercados intelectuais nacionais. Estes, mais independentes que os franceses em relação às restrições tanto intelectuais quanto

\footnotetext{
${ }^{62}$ P. Mengue, op.cit, p. 50.
} 
institucionais locais, estarão, portanto, potencialmente mais disponíveis a todos os tipos de experimentos.

E geralmente, pode-se pensar em todos esses estudantes que, após 68, estarão em ruptura, mais ou menos radical, com o universo escolástico tradicional, e isso por razões relacionadas à história coletiva, à sua trajetória social, escolar etc. O limite extremo de tudo isso sendo o do "esquizo", do "animal" ou - outro personagem deleuziano e nietzschiano muito valorizado - da "criança", os quais a priori eram todos bem-vindos à Vincennes, destacando assim estilisticamente as especificidades do lugar. Esse fato não deixa de conferir um caráter um tanto "milagroso"63 ao estabelecimento e provoca um efeito repulsivo em algumas pessoas, especialmente aquelas chocadas com a vetustez das instalações, assim como com o caráter aparentemente muito relaxado de tudo aquilo.

De modo geral pode-se pensar que a "unidade misteriosa" do público de Vincennes, que aliás tanto fascinava Deleuze, estava principalmente fundada em uma homologia de posição, ou seja, Vincennes, que muitas vezes fora apresentada como uma “instituição anti-institucional”, é um dos lugares em que, após 68, se concentrará, e isso tanto do lado dos estudantes e professores quanto do pessoal administrativo e técnico, frequentemente esquecido nas histórias universitárias, toda uma série de agentes que ocupam uma posição mais ou menos marginal, e portanto dominada, nas instituições tradicionais. Daí decorre uma relação estruturalmente crítica com o mundo acadêmico, e mais amplamente com o mundo social e político.

Assim, neste momento, parece interessante voltar à teoria da dupla recepção de Deleuze. Pois, através desta teoria, Deleuze, finalmente, opõe dois públicos: de um lado, o dos profanos, dos laicos, e mais precisamente "selvagens" e outros "bárbaros", dotados de uma compreensão não filosófica por percepções e afetos, implicitamente identificados aqui com seu público em sentido mais amplo. E do outro, o dos profissionais da disciplina, suspeitos de permanecer numa compreensão estritamente conceitual e, portanto, puramente acadêmica. De um lado a vida, o sensível e os usos profanos externos mais ou menos experimentais, e potencialmente subversivos da filosofia. Do outro, o conceito lá onde, como ele escreve, "o excesso de saber" é suspeito de matar "o

\footnotetext{
${ }^{63}$ Do original, "cour des miracles". (N.T.)
} 
vivente na filosofia" ${ }^{64}$. Saber escolar, reificante e mortífero, que em última análise serve apenas para a reprodução da ordem estabelecida, quer seja filosófica, política, social ou outra.

\section{Deleuze, príncipe da boemia}

O público de Deleuze reunirá, portanto, uma espécie de boemia tanto filosófica e artística quanto política, particularmente cosmopolita. Esta boemia proliferará muito na França no pós-68 com o advento do esquerdismo contracultural que sucederá ao esquerdismo marxista mais ou menos autoritário ${ }^{65}$. Ela constitui a antítese quase perfeita desses produtos conformes escolarmente que caracterizam os antigos alunos das classes preparatórias e da Escola Normal, que formam a pequena e grande nobreza escolar francesa e cujo conformismo em matéria de escolha de temas de pesquisa, orientador, instituição, etc. não precisam mais ser demonstrados. ${ }^{66}$ Alunos dentre os quais são recrutados prioritariamente os futuros profissionais da filosofia, neste caso os professores de filosofia tanto do ensino médio quanto superior. E isso é o que explica sem dúvida, em parte, de acordo com Sébastien Charbonnier, autor de um Deleuze pedagogo muito interessante, o fato de Deleuze admitir que detestava os estudantes de filosofia $^{67}$, embora ele tenha sido um deles e, particularmente, brilhante... Assim, poderse-ia qualificar Deleuze, cujo gosto refinado pelas margens, pelo de fora, pelo improvável, etc., não precisa mais ser demonstrado: trata-se de uma espécie de príncipe da boemia ${ }^{68}$.

E aqui se pode ver como a crítica deleuziana pode, por homologia, ser transferida para muitos outros contextos disciplinares, sociais, mas também nacionais. $E$ assim se compreende melhor o impacto internacional desta filosofia. O paradoxo é que uma configuração institucional singular, neste caso a de Vincennes dos anos 70, tenha podido

\footnotetext{
${ }^{64}$ Gilles Deleuze, Pourparlers, Paris: Minuit, 1990, p. 190.

${ }^{65}$ Sobre este ponto ver as análises de Gérard Mauger relativas à "boemia popular", que com a sua "boa vontade cultural”, mesclada de um espírito antiescolar, formara um componente não negligenciável do público de Vincennes.

${ }^{66}$ Cf. Charles Soulié, « Anatomie du goût philosophique », Actes de la recherche en sciences sociales, $n^{\circ} 109$, octobre 1995.

${ }^{67}$ S. Charbonnier, op.cit, p. 18.

68 Deleuze produzia livros habitados pelo "de fora", por uma multiplicidade desligada, selvagem, "não formada” de forças (Proust et les signes, Paris: PUF, 1970, p. 125), pois a vida é o de fora. E esse de fora é uma potência que não pode ser dita e enunciada como tal, mas deve ser captada (Ibid, p. 126).
} 
contribuir para a produção de sistemas filosóficos de alcance universal. Daí, sem dúvida, a existência do mito de Vincennes, o que justifica minha fala para vocês hoje.

Agradeço-lhes a escuta.

\section{Referências}

BEAUBATIE Yannick, « Grandeur de Gilles Deleuze », in Y. BEAUBATIE (dir.), Tombeau de Gilles Deleuze, Tulle: Mille Sources, 2000.

BERNOLD André, « Suidas », Philosophie, n 47, septembre 1995.

BOUDINET Gilles, Deleuze et l'anti-pédagogie: vers une esthétique de l'éducation, Paris: L'Harmattan, 2012.

BOURDIEU Pierre, Homo academicus. Paris, Minuit, 1984.

BOURDIEU Pierre, “In memoriam Gilles Deleuze”, Liber, 28, septembre, 1996.

CHARBONNIER Sébastien, Deleuze pédagogue, la fonction transcendantale de l'apprentissage et du problème, Paris: l'Harmattan, 2009.

CHATELET François, « Disparité et non hiérarchie », in Vincennes ou le désir d'apprendre, Jacqueline BRUNET (dir.), Paris: Ed. Alain Moreau, 1979.

CRESSOLE Michel , Deleuze, Paris: Ed. Universitaires, 1973. 
DELEUZE Gilles et PARNET Claire, « De la supériorité de la littérature anglaiseaméricaine », in Dialogues, Paris: Flammarion, 1977.

DELEUZE Gilles, Proust et les signes, Paris: PUF, 1970.

DELEUZE Gilles, Spinoza philosophie pratique, Paris: Minuit, 1981.

DELEUZE Gilles, Pourparlers, Paris: Minuit, 1990.

DELEUZE Gilles, GUATTARI Félix, Qu'est-ce que la philosophie? Paris: Minuit, 1991.

DELEUZE Gilles, L'Abécédaire de Gilles Deleuze, film de Pierre-André Boutang, Paris:

Éditions du Montparnasse, 2004.

DELEUZE Gilles, Pourparlers, Paris: Minuit, 1990.

DJIAN Jean-Michel (dir.), Vincennes, une aventure de la pensée critique, Paris: Flammarion, 2009.

DOSSE François, Gilles Deleuze Félix Guattari, biographie croisée, Paris: La Découverte, 2007.

ÉRIBON Didier, Michel Foucault, Paris: Flammarion, 1991.

ÉRIBON Didier, Michel Foucault et ses contemporains, Paris: Fayard, 1994.

JAEGLE Claude, Portrait oratoire de Gilles Deleuze aux yeux jaunes, Paris: Presses universitaires de France, 2005.

KALINOWSKI Isabelle, “La voix de Max Weber et le charisme professoral”. In Leçons wébériennes sur la science et la propagande, ouvrage reproduit à la suite de sa traduction de La Science, profession et vocation de Max Weber, Marseille: Agone, 2005.

MARX Karl, Editorial $n^{\circ} 179$ de la Gazette de Cologne, texte reproduit dans Karl Marx et Friedrich Engels, Sur la religion, Les éditions sociales, 1968. Disponible sur:

https://www.marxists.org/francais/marx/works/oo/religion/Marx_Engels_sur_la_religion.p df

PINHAS Richard, «Deleuze, le dehors entre les murs: entretien avec Richard Pinhas », Europe, $n^{\circ}$ 996, avril 2012.

SOULIE Charles, "Anatomie du goût philosophique », Actes de la recherche en sciences sociales, $n^{\circ} 109$, octobre 1995.

SOULIE Charles (dir.), Un mythe à détruire? Origines et destin du Centre universitaire expérimental de Vincennes, Vincennes- Saint-Denis: Presses universitaires de Vincennes, 2012. 
SOULIÉ Charles, "Uma tentativa de democratização universitária na França: história da Universidade de Paris VIII Vincennes (1968-1980)", publicado na Revista Linhas em 2014. Disponível em:

http://www.revistas.udesc.br/index.php/linhas/article/view/1984723815292014042/pdf_2.

TESSARECH Bruno, Vincennes, Paris: Nil éditions, 2011.

TOURNIER Michel, Le vent Paraclet, Paris: Gallimard, 1977.

WARESQUIEL (de) Emmanuel (dir.), Le Siècle rebelle, Dictionnaire de la constestation au XXe siècle, Paris: Larousse, 1999.

WEBER Max, Sociologie de la religion, traduction d'Isabelle Kalinowski, Paris:

Flammarion, 2006.

Recebido em: 28/01/2015 Aprovado em: 19/05/2015

Universidade do Estado de Santa Catarina - UDESC Programa de Pós-Graduação em Educação - PPGE Revista Linhas

Volume 16 - Número 32 - Ano 2015 revistalinhas@gmail.com 